\title{
Anesthesia for Osteosynthesis of Femur in a Cane Toad (Rhinella marina)
}

\author{
Rochelle Gorczak $\oplus^{1}$, Marilia Avila Valandro ${ }^{1}$, Érika Fernanda Villamayor Garcia ${ }^{2}$, Ana Carolina Coelho ${ }_{\odot}$, \\ Bruna Zafalon da Silva ${ }^{1} \&$ André Vasconcelos Soares ${ }^{3}$
}

\begin{abstract}
Background: The taxonomic order Anura is composed of frogs and toads, with approximately 6,000 species worldwide, of which 900 species are found in Brazil. Rhinella marina, popularly known as "sapo-cururu," is the most commonly found frog in Brazil. Although most of these animals are found in research laboratories and zoos, they are increasingly being reared as pets. Therefore, sedation or anesthesia is often necessary for these animals to facilitate medical care, complementary examinations, or surgical procedures. However, there are only a few reports of anesthesia in frogs. Therefore, the present report aimed to describe the anesthetic protocol for femoral osteosynthetic surgery in an adult cane toad.

Case: An adult cane toad presented with a history of difficulty in moving the left hindlimb and loss of limb movements. Radiography showed a simple, complete, transverse, and closed average shaft of the left femur and bone shaft fracture deviation. The animal was referred for an osteosynthetic surgery to stabilize the fracture. Animal restraint was performed using humidified gloves on the operating table. As premedication, ketamine, meloxicam, and morphine were administered, and general anesthesia was induced with isoflurane through a face mask. The anesthesia was maintained with isoflurane through a drip on the animal's back for cutaneous absorption. Lidocaine (2\%) anesthetic gel was applied on the incision line to complement the somatic analgesia. The fracture was fixed using an intramedullary Kirschner pin. The heart rate was measured based on the beep of the arterial pulse using a Doppler ultrasonic device, respiratory rate was recorded by visual observation of the animal's respiratory motion, and body temperature was assessed using an esophageal digital thermometer - all of these remained stable during the procedure. Morphine, enrofloxacin, and meloxicam were administered postoperatively. The animal was discharged from the hospital seven days after the surgery, and 14 days later, the animal was deemed clinically stable with favorable wound healing.

Discussion: Toads use their skin to breathe and maintain osmotic balance. Therefore, their skin is extremely sensitive to dehydration, requiring constant wetting. General anesthesia in amphibians is recommended for prolonged and painful procedures, as in the present case. Different anesthetics, analgesics, and associated drugs may be used. Ketamine is often used for chemical restraint in amphibians, and the induction and recovery times may vary due to sensitivity and drug resistance. Inhalational anesthesia with isoflurane may also be effective; in the present case, the anesthetic was administered using a mask placed on the frog's skin, without any irritation. Analgesia is essential for any animal, and amphibians have opioid receptors that may be used as targets of non-steroidal anti-inflammatory agents. As indicated for all species, the animal was monitored throughout the procedure. Assessment of heartbeat is the simplest way to monitor anesthesia using Doppler (on the heart or throat); in the present case, was placed on the axillary artery for clear auscultation. In addition, other parameters, such as temperature and primary respiratory movements, were monitored. Anesthetic recovery can take hours or even days, whereas excretion depends on the metabolic rate of each animal. In the present case, recovery was observed $4 \mathrm{~h}$ after completion of the procedure, using fresh water on the animal's body to accelerate recovery, as indicated in the literature. This case demonstrated that anesthesia and medications used for anesthesia induction, maintenance, and recovery are safe in toads. For cane toads, during femoral osteosynthesis, this anesthetic procedure has never been described previously in the literature. Finally, such information can aid veterinarians in performing safe and adequate analgesic and anesthetic procedures for the wellbeing of animals.
\end{abstract}

Keywords: amphibians, analgesia, surgery, skin absorption. 
R. Gorczak, M.A. Valandro, E.F.V. Garcia, et al. 2021. Anesthesia for Osteosynthesis of Femur in a Cane Toad (Rhinella marina). Acta Scientiae Veterinariae. 49(Suppl 1): 703.

\section{INTRODUCTION}

The Anura order is represented by frogs and toads, there are about 6,000 species worldwide, and 900 of them are found in Brazil [11]. Rhinella marina, popularly known as "sapo-cururu", is most commonly frog found in Brazil, and has a pair of glands with poison, on the back of the head, with high toxic potential [10]. Although most of these animals are found in research labs and zoos, increasingly, they are created as pets. Therefore, it is often necessary to sedate or anesthesiate these animals, to facilitate the management for medical care, complementary examinations or surgical procedures [11,12].

Amphibians are usual subjects of research, mainly in biology, however, information of anesthetic agents which can be used are fairly limited in these animals [5]. The chemical restraint in these animals is often necessary to evaluate the patient, and in most cases, restraint drugs such as isoflurane, ketamine or specific drugs for amphibians like tricaine methanesulfonate are used [15].

Some reports of anesthesia in frogs are found in the literature, but, basically, in the international literature $[1,2,4,5,8,12,13,16]$. Due to the scarcity of reports on the subject at the national level, the aim of this report, was to report anesthetic protocol and the monitoring of vital parameters evaluated in an adult cane toad submitted to femoral osteosynthesis surgery.

\section{CASE}

An adult cane toad, female, weighing $0.4 \mathrm{~kg}$, was referred to the University Veterinary Hospital of Santa Maria, RS, Brazil with a history of moving the left hindlimb difficulty. At physical examination, it

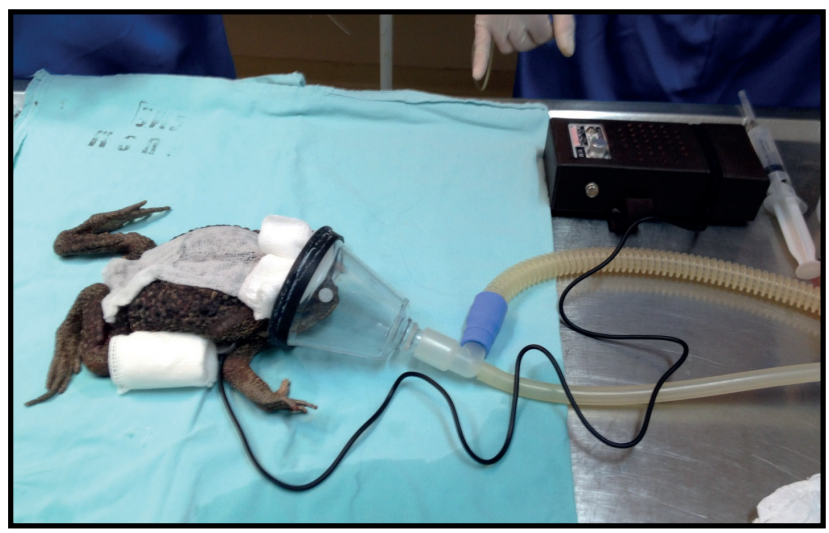

Figure 1. Wetted bandage with distilled water applied on the body of the cane toad, for maintenance of the patient's hydration. Realization of the anesthetic induction by facial mask with vaporized isoflurane in 100\% oxygen. was observed loss of limb movements. The animal was taken to the radiographic examination, evidencing simple, complete, transverse and closed in average shaft of left femur and bones haft fracture deviation. With clinical and radiological findings, the animal was referred to surgery to stabilize the fracture.

For realization of osteosynthesis, the patient remained without solid fasting for $12 \mathrm{~h}$. The animal restraint was performed with the use of humidified gloves by the operating table. As a premedication, it was used combinations of ketamine ${ }^{1}$ [Cetamin ${ }^{\mathrm{TM}}-60 \mathrm{mg} / \mathrm{kg}, \mathrm{IM}$ ], meloxicam $^{2}$ [Maxicam $^{\mathrm{TM}} 0.2 \%-0.4 \mathrm{mg} / \mathrm{kg}, \mathrm{SC}$ ] and morphine $^{3}$ [Dimorf $\left.^{\mathrm{rM}}-40 \mathrm{mg} / \mathrm{kg}, \mathrm{SC}\right]$. After $10 \mathrm{~min}$, it was held induction of general anesthesia with isoflura$\mathrm{ne}^{1}$ (Isoforine $^{\mathrm{TM}}$ ) diluted in oxygen at $100 \%$ in universal vaporizer through system without rebreathing gas (via face mask), for maximum vaporization to achieve the desired effect, which is the loss the righting reflex. In addition to this, we used a bandage on the patient's body, wetted with distilled water every 5 minutes, thus keeping the patient hydrated (Figure 1). For maintenance this anesthesia was used vaporized isoflurane ${ }^{1}$ in oxygen at $100 \%$, with open circuit in the first 25 min. Subsequently, it was given oxygen via face mask until the end of the procedure. After the first $25 \mathrm{~min}$, the anesthesia was maintained through dripping isoflurane $^{1}$ (total volume used was $6 \mathrm{~mL}$ ) on the animal's back by cutaneous absorption (Figure 2). In addition, 10 min before starting the surgical procedure, it was used lidocaine $2 \%$ anesthetic gel ${ }^{4}\left(\operatorname{Lidogel}^{\mathrm{TM}}\right)$ on the incision line, to complement the somatic analgesia.

After obtaining surgical anesthesia the lateral incision of skin, muscles of dilatation and location of bone fragments was performed. These were presented

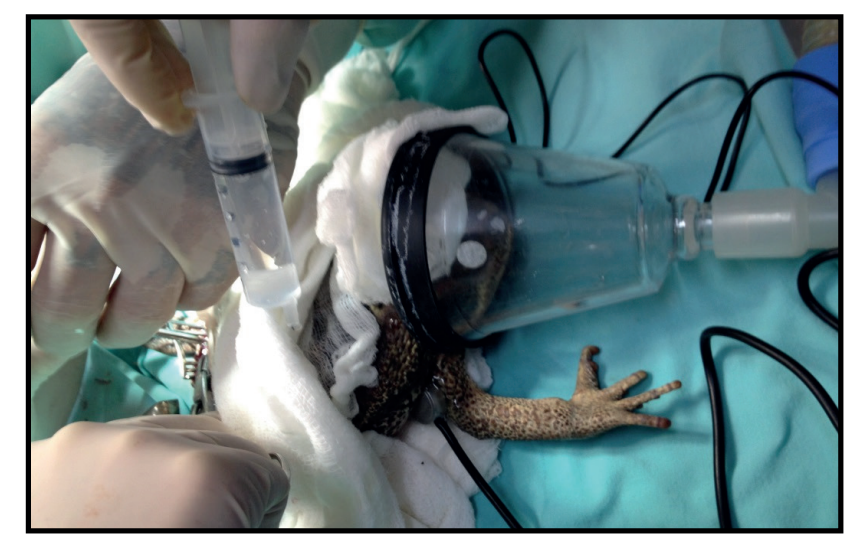

Figure 2. Anesthetic isoflurane maintenance performed by dripping over the back of cane toad. 
R. Gorczak, M.A. Valandro, E.F.V. Garcia, et al. 2021. Anesthesia for Osteosynthesis of Femur in a Cane Toad (Rhinella marina). Acta Scientiae Veterinariae. 49(Suppl 1): 703.

covered by fibrous tissue and the spinal canal closed due to an earlier healing process, confirming the initial suspicion that it was an old fracture. With the assistance of a scalpel and tweezers gouge was held opening of the spinal canal and revival of the edges of the bone fragments, respectively. A plate-rod technique was performed (intramedullary pin of association and bone plate). Firstly, we used an intramedullary pin Kirschner ${ }^{5}$ (Fio de Kirschner Ortovet ${ }^{\mathrm{TM}}$ ) introduced in a retrograde manner for alignment of the bone fragments. And then the fracture was fixed through the use of a straight bone plate with 5 bolts, 3 bolts placed in the distal and 2 proximal fragments. Thus, the approximation was performed with continuous single muscle suture, polyglycolic acid ${ }^{6}$ yarn 4.0 (Ácido Poliglícólico ${ }^{\mathrm{TM}}$ ) and skin sutures with the same type of yarn, using for such suture standard Wolff. At the end of the skin suture was applied to an enamel layer to waterproof the area.

Heart rate (HR) was measured by the beep of the arterial pulse, using for such a Doppler Ultrasonic device, and its probe positioned in the right forelimb on the axillary artery (Figure 3 ). The respiratory rate was recorded by visual observation of patient respiratory moves and body temperature through an esophageal digital thermometer. The parameters recorded during the procedure remained stable, with 4 breaths per minute during the first $30 \mathrm{~min}$ and then, the respiratory moves observation was not possible. The HR remained between 36 and 56 bpm and body temperature remained between $22.8^{\circ} \mathrm{C}$ to $24.3^{\circ} \mathrm{C}$.

The duration of surgery and anesthesia was 105 and $160 \mathrm{~min}$, respectively. At the end of the procedure, the patient was immersed for $20 \mathrm{~min}$ in a bowl filled with water which was coupled with a hose with oxygen bubbling (Figure 4). Eight min after the immersion the

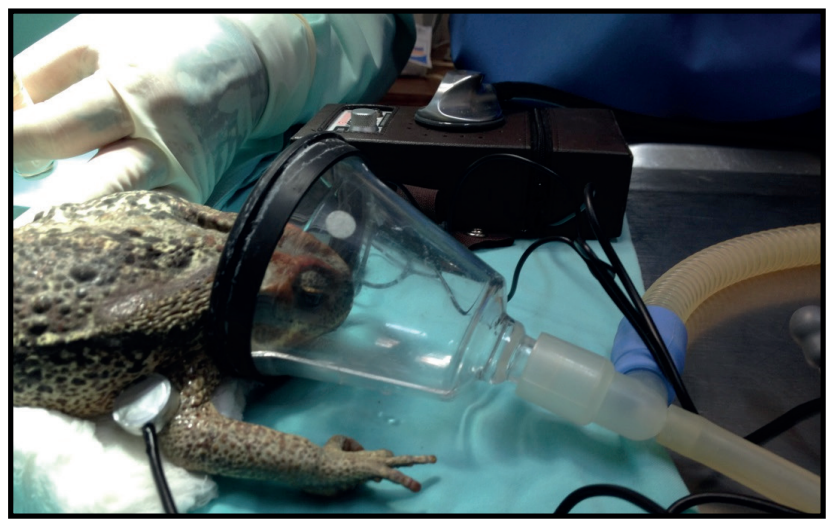

Figure 3. Using the ultrasonic Doppler with the probe positioned in the right thoracic member on the axillary artery to heart rate monitoring in cane toad. respiratory movements returned, however, with low amplitude. Four $h$ after the procedure, the patient had already recovered, moving slowly and breathing being viewed through the breadth of the thorax.

In the postoperative was administered morphi$\mathrm{ne}^{3}$ [20 mg/kg, topically, BID, 2 days], enrofloxacin ${ }^{7}$ [Chemitril $^{\text {TM }} 2.5 \%-10 \mathrm{mg} / \mathrm{kg}, \mathrm{SC}$, SID for 7 days], and meloxicam ${ }^{2}$ [Maxicam $^{\mathrm{TM}} 0.2 \%-0.4 \mathrm{mg} / \mathrm{kg}, \mathrm{SC}$, SID for 4 days]. The animal was discharged from the hospital 7 days after the surgery, and 14 days after, the patient was clínically stable with good healing of wounds access.

\section{DISCUSSION}

The skin of amphibians is an adaptation, due to its high permeability and for being the most used way to breath and perform osmotic balance. So, it is extremely sensitive to dehydrate, requiring it to constantly be wetted. As held in the present report, for patient restraint, it is recommended to use humidified gloves with water and without talc, due to the fact this can be absorbed by the skin and cause physiological changes during surgery or skin irritation $[6,10,11,14,15]$.

We opted for the $12 \mathrm{~h}$ establishment of preoperative fasting, although some authors claim that amphibians do not require pre anesthesia fasting, because the larynx remains closed even during general anesthesia, reducing the chance of false road [14]. However, some authors recommend always performing fasting for amphibians, the possibility, albeit rare, occurs during anesthesia and regurgitation due to slow metabolism of these animals [7,11].

General anesthesia in amphibians is recommended for prolonged and painful procedures. Anesthesia is evaluated through the right in reflex (inability

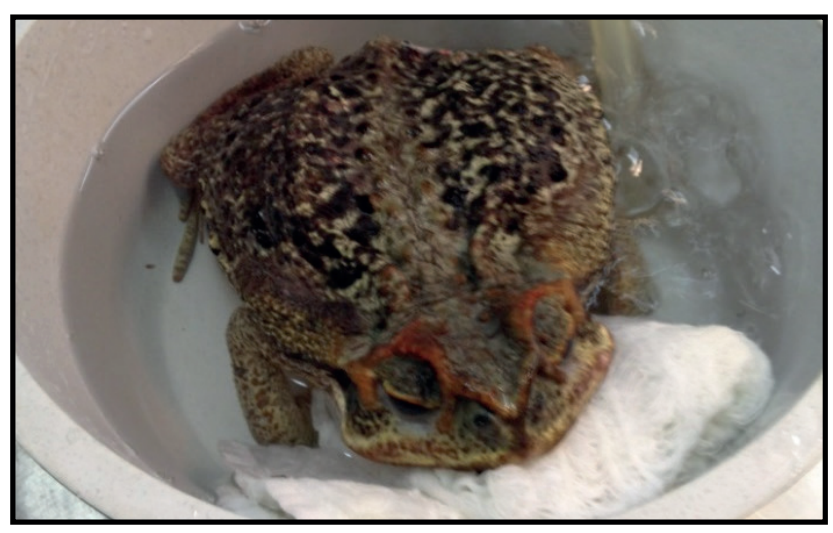

Figure 4. Cane toad immersed in water with oxygen bubbling for anesthetic recovery. 
to be able to maintain their natural posture) $[7,8]$ pain and respiratory efforts associated with loss of corneal reflex, and the withdrawal reflex is the last to disappear. As anesthetic depth increases, loss of abdominal breathing, and decreased gular movement, which in turn disappear when it reaches surgical plan, with all reflections absent, leaving only the heart beats. At this point, it is common to start with cutaneous respiration to prevent hypoxia, as noted in the present report by the lack of respiratory movement and the patient remained stable during the procedure. It enhances the anesthetic by dripping anesthetic on the patient's body, and can be removed from the anesthesia placing it in distilled water with oxygen $[3,7,10,14]$.

Although there is no consensus among authors, because these animals are ectothermic, they should keep these animals anesthetized with an ambient temperature around $28^{\circ} \mathrm{C}$ [9]. An performed experiment maintained the room at a temperature of approximately $26^{\circ} \mathrm{C}$ [8]; others recommend keeping between 15 to $23^{\circ} \mathrm{C}[3,14]$. However, for other authors the ideal temperature ranges from 21 to $25.4^{\circ} \mathrm{C}[12,15]$, and the humidity should remain below $50 \%$ [15]. In this case, the temperature in this patient during the procedure ranged from $22,8^{\circ} \mathrm{C}$ to $24,3^{\circ} \mathrm{C}$.

Ketamine is often used for chemical restraint in amphibians [6,9] the induction and recovery time may vary due to sensitivity and drug resistance $[7,10]$. In these animals the drug may be administered intramuscularly, subcutaneously, intravenously or through the dorsal lymphatic sacs. The recommended dosage varies from 75 to $100 \mathrm{mg} / \mathrm{kg}$ [15], however, is described as a dose of between 50 to $150 \mathrm{mg} / \mathrm{kg}$ [7]. In this study, we used $60 \mathrm{mg} / \mathrm{kg}$ of premedication, and it was possible to realize the induction in $10 \mathrm{~min}$, and recover from anesthesia in $4 \mathrm{~h}$. If needed to strengthen with this drug during anesthesia, it should be administered a single dose more, as these animals have a slow metabolism and differential, reducing the excretion of the drug, and consequently delaying the patient's return after the procedure $[1,2]$. In this case report, only one dosage of medication was required.

The tricaine methanesulfonate is the most commonly used local anesthetic in fish and amphibians in the United States of America reported that during the anesthetic recovery, some patients had cyanosis and dyspnea $[3,5,7,11-13,15,16]$. In a study that was used ometomidate hydrochloride, and observed cardiovascular effects like marked bradycardia, as well as long-anesthetic recovery [2]. In the literature it has not described the use of lidocaine in this kind of patients. However, with the anesthetic protocol used in the patient of this report, these cardio-respiratory effects were not observed.

Inhalatory anesthesia can also be effective. The sevoflurane, desflurane, as Isoflurane, used in the patient of this report, can be supplied by camera [8], noting that the animals use the skin for gas exchange. Some species of amphibians are sensitive to gaseous anesthetics, with skin irritation $[4,7,11,14,15]$. However, as soon as the animal in the present report, this side effect is not observed when isoflurane is placed on the skin frogs [10]. Topical administration of isoflurane can be quite effective in these animals, patients submitted to anesthesia with this dermal medication remained in surgical plan for 45 to $80 \mathrm{~min}[14,15]$, the same time observed in this report.

Amphibians have opioid receptors and can be used as non-steroidal anti-inflammatory $[6,11]$. The morphine use causes analgesia with peak effect in 60 to $90 \mathrm{~min}$. In these animals, the drug does not cause appetite or behavioral changes as observed in other species [7,11]. Both drugs were used in the reporting patient, getting expected analgesia without presenting withdrawal reflex, and little changes in cardiorespiratory parameters.

Using the heartbeat parameter is the simplest way to monitor the anesthesia [14], and it can be performed by electrocardiogram and use of Doppler ultrasound (on heart or throat) $[2,7,9,11,12]$. Unlike mentioned in the literature in this report, the Doppler was placed on the axillary artery, getting a clear auscultation. The animal bearing hypothermia, HR and oxygenation also decrease [1]. As for monitoring of respiratory frequency, it usually occurs through observation of primary respiratory movements, as performed in this case.

Anesthetic recovery can take hours or even days, whereas the excretion depends on the metabolism rate of each patient. Reversal of anesthesia may be made by placing fresh or distilled water and hydrogen peroxide on the skin animal $[7,9,14]$. In the patient of this report, the recovery was observed $4 \mathrm{~h}$ after the end of the procedure.

The protocol used was effective, achieving analgesia and surgical plan for the patient during the 
femur osteosynthesis. This report emphasizes the importance of knowledge of an appropriate anesthetic protocol and evaluation of vital parameters in different species. The improvement of such information by the veterinarian provides a safe and adequate analgesic and anesthetic procedure for the wellbeing of the patient.

\section{MANUFACTURERS}

${ }^{1}$ Syntec do Brasil Ltda. Cotia, SP, Brazil.

${ }^{2}$ Ourofino Saúde Animal Ltda. Cravinhos, SP, Brazil.
${ }^{3}$ Cristália Produtos Químicos e Farmacêuticos Ltda. São Paulo, SP, Brazil.

${ }^{4}$ Brainfarma Indústria Química e Farmacêutica S.A. Anápolis, GO, Brazil.

${ }^{5}$ Ortovet-Ortopedia Veterinária Comercial Eireli. São Paulo, SP, Brazil.

${ }^{6}$ Shalon Fios Cirúrgicos Ltda. São Luís de Montes Belos, GO, Brazil. ${ }^{7}$ Chemitec Agro-Veterinária Ltda. Ipiranga, SP, Brazil.

Declaration of interest. The authors report no conflicts of interest. The authors alone are responsible for the content and writing of the paper.

\section{REFERENCES}

1 Bícego-Nahas K.C., Gargaglioni L.H. \& Branco L.G.S. 2001. Seasonal Changes in the Preferred Body Temperature, Cardiovascular, and Respiratory Responses to Hypoxia in the Toad. Bufo paracnemis. Journal of Experimental Zoology. 289(6): 359-365.

2 Doss G.A., Nevarez J.G., Fowlkes N. \& Cunha A.F. 2014. Evaluation of metomidate hydrochloride as an anesthetic in leopard frogs (Rana pipiens). Journal of Zoo and Wildlife Medicine. 45(1): 53-59.

3 Fan Y., Yue X., Xue F., Brauth S.E., Tang Y. \& Fang G. 2018. The right thalamus may play an important role in anesthesia-awakening regulation in frogs. Peer J. 6: e4516.

4 Fischer D., Lorenz N., Heuser W., Kämpfer P., Scholz H.Z. \& Lierz M. 2012. Abscesses associated with a Brucella inopinata-like bacterium in a big-eyed tree frog (Leptopelis vermiculatus). Journal of Zoo and Wildlife Medicine. 43(3): 625-628.

5 Hernandez S.E., Sernia C. \& Bradley A.J. 2013. The effect of three anaesthetic protocols on the stress response in cane toads (Rhinella marina). Veterinary Anaesthesia and Analgesia. 39(6): 584-590.

6 Jaramillo E.Y. 2012. Urgência em Anfíbios. In: Rabelo R. (Ed). Emergências de Pequenos Animais Condutas Clínicas e Cirúrgicas no Paciente Grave. Rio de Janeiro: Elsevier, pp.621-625.

7 Longley L.A. 2008. Amphibian anaesthesia. In: Longley L.A. (Ed). Anaesthesia of Exotic Pets. London: Saunders Elsevier, pp.245-258.

8 Morrison K.E., Strahl-Heldreth D. \& Clark-Price S.C. 2016. Isoflurane, sevoflurane and desflurane use in cane toads (Rhinella marina). Veterinary Record Open. 3(1): 000185.

9 Natalini C.C. 2007. Protocolo de anestesia geral volátil nas Espécies animais. In: Natalini C.C. (Ed). Teoria e Técnicas em Anestesiologia Veterinária. Porto Alegre: Artmed, pp.125-167.

10 Oliveira P.M.A. 2003. Anfíbios. In: Oliveira P.M.A. (Ed). Animais Silvestres e Exóticos na Clínica Particular. São Paulo: Roca, pp.135-196.

11 Paula C.D. \& Toledo L.F. 2014. Anfíbios (Rã, Sapo e Cobra-cega). In: Cubas Z.S., Silva J.C. \& Catão-Dias J.L. (Eds). Tratado de Animais Selvagens. 2.ed. São Paulo: Roca, pp.132-151.

12 Posner L.P., Bailey K.M., Richardson E.Y., Motsinger-Reif A.A. \& Harms C.A. 2013. Alfaxalone anesthesia in bullfrogs (Lithobates catesbeiana) by injection or immersion. Journal of Zoo and Wildlife Medicine. 44(4): 965-971.

13 Speare R., Speare B., Muller R. \& Bishop P. 2014. Anesthesia of tadpoles of the southern brown tree frog (Litoria ewingii) with isoeugenol (AQUI-S). Journal of Zoo and Wildlife Medicine. 45(3): 492-496.

14 Stetter M. 2007. Amphibians. In: West G., Heard D. \& Caulket N. (Eds). Zoo Animal \& Wildlife Immobilization and Anesthesia. Hoboken: Blackwell Publishing, pp.205-209.

15 Wright K.M. 2006. Overview of Amphibian medicine. In: Mader D.R. (Ed). Reptile Medicine and Surgery. 2nd edn. St. Louis: Saunders Elsevier, pp.941-971.

16 Young S., Speare R., Bergerand L. \& Skerratt L.F. 2012. Chloramphenicol with fluid and Electrolyte therapy cures terminally ill green tree frogs (Litoria caerulea) with chytridio mycosis. Journal of Zoo and Wildlife Medicine. 43(2): 330-337. 